\title{
Significance of the serum CA-125 level in intrauterine insemination cycles
}

\author{
Seung Ah Choe, Seung-Yup Ku, Byung Chul Jee, Chang Suk Suh, Seok Hyun Kim, Young Min Choi, Jung Gu Kim, \\ Shin Young Moon
}

Department of Obstetrics and Gynecology, Seoul National University College of Medicine, Institute of Reproductive Medicine and Population, Medical Research Center, Seoul National University College of Medicine, Seoul, Korea

Objective: There are limited data regarding the significance of elevated serum CA-125 level during IUI cycles, even though it is used widely during the initial evaluation of infertile patients. The aim of this study was to investigate the prognostic value of serum CA- 125 levels during IUI cycles.

Methods: Among the patients with controlled ovarian stimulation and IUI cycles at Seoul National University Hospital from Jan 2005 through Dec 2009, 92 cases with no identified endometriotic lesion, ovarian tumor, salpingeal lesion, or uterine myoma were selected. To compare the clinical characteristics between the pregnancy group and the non-pregnancy group, the Mann-Whitney U test and Fisher's exact test were used. Results: The overall pregnancy rate was 18.5\% (17/92). The pregnancy group showed a higher number of follicles $16 \mathrm{~mm}$ in diameter $(p=0.036)$, endometrial thickness $(p<0.001)$, ampules of gonadotropin $(p=0.009)$, and higher body mass index $(p=0.022)$ than the non-pregnancy group. No significant difference was observed in the serum CA-125 level or the proportion of patients with CA-125 exceeding 17 IU/mL between the two groups.

Conclusion: The prognostic value of serum CA-125 level among infertile patients with IUI cycles is considered limited.

Keywords: CA-125 Antigen; Intrauterine Insemination; Human

\section{Introduction}

IUI is a common procedure applicable in cases of cervical infertility, male factor infertility, anovulation, endometriosis with a healthy fallopian tube, and unexplained infertility. Endometriosis, uterine myomas, acute and chronic salpingitis, and pelvic inflammatory disease are female factors that are known to have a negative impact on the pregnancy rate during the IUI cycle [1-3]. Still, the mechanisms by

Received: Dec 1, 2010 · Revised: Mar 4, 2011 • Accepted: Jun 20, 2011 Corresponding author: Shin Young Moon

Department of Obstetrics and Gynecology, Seoul National University College of Medicine, Institute of Reproductive Medicine and Population, Medical Research Center, Seoul National University College of Medicine, 28 Yeongeon-dong, Jongno-gu, Seoul 110-744, Korea

Tel: +82-2-2072-3529 Fax:+82-2-762-3599 E-mail: shmoon@snu.ac.kr

This is an Open Access article distributed under the terms of the Creative Commons Attribution Non-Commercial License (http://creativecommons.org/licenses/by-nc/3.0/) which permits unrestricted non-commercial use, distribution, and reproduction in any medium, provided the original work is properly cited. which these factors affect the outcome of infertility treatment remain unclear.

CA-125 is a high-molecular-weight glycoprotein that presents on the epithelium of the fallopian tubes, endometrium, endocervix, as well as other tissues of Müllerian origin [4,5]. Measurement and monitoring of CA-125 level may be a simple and inexpensive test that can identify a subgroup of patients who are likely to have pelvic pathologies such as endometriosis, uterine myomas, acute and chronic salpingitis, ovarian tumors, and pelvic inflammatory disease, which are not detectable in the initial examination [5]. Little data is currently available regarding the cutoff values for screening for a uterine myoma or an adnexal mass. Previous studies focused mainly on the detection of endometriosis using the serum CA-125 level and a serum level of $17-35 \mathrm{U} / \mathrm{mL}$ has been reported to have sensitivities of 20$94 \%$ and specificities of $77-92 \%$ in detection of endometriosis grade I/IV [6-9]. Hence we hypothesized that an elevation of the serum CA125 level may be linked to a lower pregnancy rate in IUI cycles. To our 
knowledge, few studies have addressed the relationship between the serum CA-125 level and the outcome of IUI. In this study, we aimed to explore whether the serum CA-125 level differs according to the outcomes of IUI cycles.

\section{Methods}

Patients who had undergone controlled ovarian stimulation and IUI cycles at Seoul National University Hospital from January 2005 to December 2009 were selected. All couples had a duration of infertility of more than one year and were eligible for superovulation and IUI cycles. Cases with a physically or sonographically identifiable endometriotic lesion, ovarian or salpingeal mass, or uterine myoma were excluded. Other pelvic abnormalities such as unilateral tubal obstruction or uterine anomaly were classified as female causes of infertility. Male factor infertility was defined by the World Health Organization criteria [10]. Serum CA-125 levels were measured on menstrual day 3 with other steroid hormones as an initial evaluation of infertility using radioimmunoassay kit (Fujirebio Diagnostics, Malvern, PA, USA).

Controlled ovarian stimulation (COS) was performed with urinary hMG (IVF-M ${ }^{\circledast}$, LG Life Sciences, Seoul, Korea) and clomiphene citrate (Clomiphene ${ }^{\circledR}$, Youngpoong Pharma, Seoul, Korea) in a dose of 150 $\mathrm{mg} /$ day given from day 3 through day 7 of the menstrual cycle. A recombinant hCG (Ovidrel ${ }^{\circledR}$, Serono, Geneva, Switzerland) in a dose of $250 \mu \mathrm{g}$ was given when either the leading follicle reached a mean diameter of $18 \mathrm{~mm}$ or two or more follicles reached a diameter of 17 $\mathrm{mm}$. IUI was then performed 36 hours later.

The luteal phase was supported by a daily application of $8 \%$ progesterone gel (Crinone ${ }^{\circledR}$, Serono, Geneva, Switzerland), initially for 14 days, starting on the day of the IUI, and continuing for another 6-8 weeks in cases with pregnancy. Clinical pregnancy was defined by the presence of an intrauterine gestational sac with fetal heartbeats at 3 to 4 weeks after insemination.

Data were analyzed with SPSS ver. 16.0 (SPSS Inc., Chicago, IL, USA). Fisher's exact test was used to compare proportions, and the MannWhitney $\mathrm{U}$ test to compare means. A $p$-values less than 0.05 were considered statistically significant.

\section{Results}

The overall pregnancy rate was $18.5 \%$ (17/92). The mean age was $33.2 \pm 3.1$ years; the mean duration of infertility was $3.4 \pm 2.2$ years, and the mean body mass index (BMI) was $22.0 \pm 5.1 \mathrm{~kg} / \mathrm{m}^{2}$. More than a third of the women (34.8\%) had achieved a prior pregnancy. The infertility factors of the subjects were identified as unexplained (28.3\%), female (62.0\%), and male (17.4\%) factors. The serum level of CA-125 ranged from 1.7 to $77.1 \mathrm{IU} / \mathrm{mL}$ in the study population. Among
Table 1. Patient characteristics according to the achievement of pregnancy

\begin{tabular}{|c|c|c|c|}
\hline \multirow{2}{*}{ Parameters } & \multicolumn{2}{|c|}{ Pregnancy } & \multirow{2}{*}{$p$-value } \\
\hline & Yes $(n=17)$ & No $(n=75)$ & \\
\hline Woman's age (yr) & $33.2 \pm 2.8$ & $33.2 \pm 3.2$ & NS \\
\hline Previous pregnancy & $23.5(4 / 17)$ & $37.3(28 / 75)$ & NS \\
\hline \multicolumn{4}{|l|}{ Etiology } \\
\hline Male factor & $29.4(5 / 17)$ & $14.7(11 / 75)$ & NS \\
\hline Female factor & $70.6(12 / 17)$ & $60.0(45 / 75)$ & NS \\
\hline Unexplained & $11.8(2 / 17)$ & $32.0(24 / 75)$ & NS \\
\hline $\operatorname{BMI}\left(\mathrm{kg} / \mathrm{m}^{2}\right)$ & $23.7 \pm 4.0$ & $21.6 \pm 5.3$ & 0.022 \\
\hline Infertility duration (yr) & $2.8 \pm 2.3$ & $3.6 \pm 2.2$ & NS \\
\hline CA-125 (IU/mL) & $21.6 \pm 16.6$ & $19.2 \pm 14.8$ & NS \\
\hline CA-125 $\geq 17(\mathrm{IU} / \mathrm{mL})$ & $58.8(10 / 17)$ & $49.3(37 / 75)$ & NS \\
\hline Number of IUI cycles & $1.6 \pm 0.9$ & $1.6 \pm 0.9$ & NS \\
\hline HSG abnormality ${ }^{a}$ & $53.8(7 / 13)$ & $34.0(18 / 53)$ & NS \\
\hline Ampules of gonadotropin & $12.1 \pm 8.8$ & $6.8 \pm 6.1$ & 0.009 \\
\hline Number of follicles $\geq 16 \mathrm{~mm}$ & $2.1 \pm 1.1$ & $1.6 \pm 0.9$ & 0.036 \\
\hline Total motile sperm count $\left(\times 10^{6}\right)$ & $51.9 \pm 20.1$ & $63.5 \pm 35.8$ & NS \\
\hline $\begin{array}{l}\text { EM thickness at the time of hCG } \\
\text { injection }(\mathrm{mm})\end{array}$ & $10.8 \pm 2.3$ & $8.3 \pm 2.4$ & $<0.001$ \\
\hline
\end{tabular}

Values are presented as mean \pm SD or $\%$ (number).

NS, not significant; BMI, body mass index; HSG, hysterosalpingography; EM, endometrium.

'Twenty-six cases had no available HSG results.

the pregnancy group and the non-pregnancy group, there was no significant difference in patient's age, incidence of nulliparity, cause and duration of infertility. The mean BMI of the pregnancy group was significantly higher than that of the non-pregnancy group $(23.7 \pm 4.0$ vs. $21.6 \pm 5.3, p=0.022$ ). The pregnancy group showed a higher number of follicles with a diameter greater than $16 \mathrm{~mm}(p=0.036)$, greater endometrial thickness $(p<0.001)$, and a greater number of gonadotropin ampoules $(p=0.009)$. No significant differences were observed in the serum CA-125 levels and the percentage of patients with CA-125 exceeding $17 \mathrm{IU} / \mathrm{mL}$ between the two groups (Table 1).

\section{Discussion}

The association of the serum CA-125 level with the outcome of in vitro fertilization has been investigated in a number of studies and the results to date have been contradictory [11-15]. To our knowledge, there have been no published studiesregarding serum CA-125 levels before COS with an IUI cycle and pregnancy. Mild elevation of the serum CA-125 level before ovarian stimulation may reflect undetected abnormal pelvic conditions such as endometriosis, uterine myomas, acute/chronic salpingitis, pelvic inflammatory disease, and ovarian tumors, all of which are known to affect fecundity $[1,16,17]$. The mechanisms of reduced fertility in minimal to mild endometriosis, distal tubal disease, or adnexal lesion are unknown. In endometri- 
osis, for example, some investigators have suggested that cytokines and growth factors secreted by the ectopic endometrial tissue may interfere with ovulation, fertilization, implantation, and embryonic development [18]. However, in the present study, we have found no significant relationship between the success of IUI and the serum CA125 level, suggesting that the measurement of CA-125 in infertile patients with no history of pelvic pathology would not be valuable in predicting IUI outcome. It is possible that subclinical pelvic pathology combined with a mild elevation of CA-125 does not have a negative effect on the outcome of IUI. Elevation of the serum CA-125 level does not directly correlate to pelvic pathologies since not all of the patients had undertaken laparoscopic examination. Singh and colleagues reported that individuals diagnosed with mild adnexal adhesion through laparoscopic examination did not have a significantly different pregnancy rate following IUI than infertility patients [16].

The pregnancy rate of IUI has been reported to range from 10 to $14 \%$ per cycle $[3,19,20]$. Many factors have been demonstrated to influence the success of IUI, though there is some disagreement about the ranking of the factors [3,19-21]. Although the size of study population was relatively small, we also observed results inconsistent with previous studies. In previous investigations, the woman's age has been shown to affect the outcome of IUI, while we found no significant difference in the patient's age according to outcome of IUI. In addition, the mean BMl of the pregnancy group was significantly higher than that of the non-pregnancy group in the present study, consistent with the result of Wang et al. [22] Since conflicting data on the association between BMI and the success of IUI have been reported, this topic needs further investigation [23-25].

In this investigation, we observed that serum CA-125 level has no prognostic value among infertile patients without gross pelvic pathology undergoing IUI cycles. Careful consideration must be given regarding routine measurement of serum CA-125 level in infertile patients with no pelvic pathology.

\section{Conflict of interest}

No potential conflict of interest relevant to this article was reported.

\section{References}

1. Jansen RP. Minimal endometriosis and reduced fecundability: prospective evidence from an artificial insemination by donor program. Fertil Steril 1986;46:141-3.

2. Toma SK, Stovall DW, Hammond MG. The effect of laparoscopic ablation or danocrine on pregnancy rates in patients with stage I or II endometriosis undergoing donor insemination. Obstet Gynecol 1992;80:253-6.
3. Nuojua-Huttunen S, Tomas C, Bloigu R, Tuomivaara L, Martikainen $\mathrm{H}$. Intrauterine insemination treatment in subfertility: an analysis of factors affecting outcome. Hum Reprod 1999;14:698-703.

4. Colacurci N, Fortunato N, De Franciscis P, Fratta M, Cioffi M, Zarcone $\mathrm{R}$, et al. Serum and peritoneal CA-125 levels as diagnostic test for endometriosis. Eur J Obstet Gynecol Reprod Biol 1996; 66:41-3.

5. Medeiros LR, Rosa DD, da Rosa MI, Bozzetti MC. Accuracy of CA 125 in the diagnosis of ovarian tumors: a quantitative systematic review. Eur J Obstet Gynecol Reprod Biol 2009;142:99-105.

6. Mol BW, Bayram N, Lijmer JG, Wiegerinck MA, Bongers MY, van der Veen $\mathrm{F}$, et al. The performance of CA-125 measurement in the detection of endometriosis: a meta-analysis. Fertil Steril 1998; 70:1101-8.

7. Gürgan T, Kişnişçi H, Yarali H, Aksu T, Zeyneloğlu H, Develioğlu 0. Serum and peritoneal fluid CA-125 levels in early stage endometriosis. Gynecol Obstet Invest 1990;30:105-8.

8. Koninckx PR, Meuleman C, Oosterlynck D, Cornillie FJ. Diagnosis of deep endometriosis by clinical examination during menstruation and plasma CA-125 concentration. Fertil Steril 1996;65:280-7.

9. Medl M, Ogris E, Peters-Engl C, Mierau M, Buxbaum P, Leodolter S. Serum levels of the tumour-associated trypsin inhibitor in patients with endometriosis. Br J Obstet Gynaecol 1997;104:78-81.

10. World Health Organization. WHO laboratory manual for the examination of human semen and sperm-cervical mucus interaction. Cambridge: Cambridge University Press; 1999.

11. Lanzone A, Fulghesu AM, Guida C, Muscatello R, Caruso A, Mancuso S. Serum CA-125 levels do not depend on ovarian steroidogenesis. Fertil Steril 1990;54:415-8.

12. Tavmergen E, Sendag F, Goker EN, Levi R. Value of serum CA-125 concentrations as predictors of pregnancy in assisted reproduction cycles. Hum Reprod 2001;16:1129-34.

13. Urbancsek J, Hauzman EE, Murber A, Lagarde AR, Rabe T, Papp Z, et al. Serum CA-125 and inhibin B levels in the prediction of ovarian response to gonadotropin stimulation in in vitro fertilization cycles. Gynecol Endocrinol 2005;21:38-44.

14. Zweers A, De Boever J, Serreyn R, Vandekerckhove D. Correlation between peripheral CA-125 levels and ovarian activity. Fertil Steril 1990;54:409-14.

15. Miller KA, Deaton JL, Pittaway DE. Evaluation of serum CA 125 concentrations as predictors of pregnancy with human in vitro fertilization. Fertil Steril 1996;65:1184-9.

16. Singh M, Goldberg J, Falcone T, Nelson D, Pasqualotto E, Attaran $M$, et al. Superovulation and intrauterine insemination in cases of treated mild pelvic disease. J Assist Reprod Genet 2001;18:26-9.

17. Werbrouck E, Spiessens C, Meuleman C, D'Hooghe T. No difference in cycle pregnancy rate and in cumulative live-birth rate 
between women with surgically treated minimal to mild endometriosis and women with unexplained infertility after controlled ovarian hyperstimulation and intrauterine insemination. Fertil Steril 2006;86:566-71.

18. Surrey ES, Halme J. Endometriosis as a cause of infertility. Obstet Gynecol Clin North Am 1989;16:79-91.

19. Merviel $P$, Heraud MH, Grenier N, Lourdel E, Sanguinet P, Copin H. Predictive factors for pregnancy after intrauterine insemination (IUI): an analysis of 1038 cycles and a review of the literature. Fertil Steril 2010;93:79-88.

20. Plosker SM, Jacobson W, Amato P. Predicting and optimizing success in an intra-uterine insemination programme. Hum Reprod 1994;9:2014-21.

21. Esmailzadeh S, Faramarzi M. Endometrial thickness and pregnancy outcome after intrauterine insemination. Fertil Steril 2007; 88:432-7.
22. Wang JX, Warnes GW, Davies MJ, Norman RJ. Overweight infertile patients have a higher fecundity than normal-weight women undergoing controlled ovarian hyperstimulation with intrauterine insemination. Fertil Steril 2004;81:1710-2.

23. Dodson WC, Kunselman AR, Legro RS. Association of obesity with treatment outcomes in ovulatory infertile women undergoing superovulation and intrauterine insemination. Fertil Steril 2006; 86:642-6.

24. Crosignani PG, Ragni G, Parazzini F, Wyssling H, Lombroso G, Perotti L. Anthropometric indicators and response to gonadotrophin for ovulation induction. Hum Reprod 1994;9:420-3.

25. White DM, Polson DW, Kiddy D, Sagle P, Watson H, Gilling-Smith $C$, et al. Induction of ovulation with low-dose gonadotropins in polycystic ovary syndrome: an analysis of 109 pregnancies in 225 women. J Clin Endocrinol Metab 1996;81:3821-4. 